\title{
Efeito da substituição do milho pela farinha da apara de mandioca em rações para poedeiras comerciais ${ }^{1}$
}

\author{
Frank George Guimarães $\mathrm{Cruz}^{2}$, Manoel Pereira Filho ${ }^{3}$, Francisco Alberto \\ de Lima Chaves ${ }^{4}$
}

\author{
1 Parte da tese de Doutorado do primeiro autor apresentada ao Programa Multi-Institucional de Pós-Graduação em Biotecnologia da \\ Universidade Federal do Amazonas - UFAM. \\ 2 DPAV/FCA/ UFAM, Manaus-AM. \\ 3 INPA, Manaus-AM. \\ ${ }^{4}$ Auxiliar de Agropecuária do DPAV/FCA/UFAM, Manaus-AM.
}

RESUMO - Avaliaram-se os desempenhos produtivo e econômico da substituição do milho pela farinha da apara de mandioca em rações para poedeiras. Foram utilizadas 200 poedeiras Lohmann LSL com 46 semanas de idade, distribuídas em 25 gaiolas. O delineamento experimental inteiramente casualizado, com cinco tratamentos e cinco repetições de oito aves por unidade experimental. Os tratamentos consistiram de cinco níveis $(0,25,50,75$ e $100 \%)$ de substituição do milho pela farinha da apara de mandioca. O consumo diário de ração apresentou efeito quadrático, com médias de 100,68; 101,00; 100,72; 99,42 e 99,50 g, nos respectivos níveis de substituição. A viabilidade, a produção de ovos e a conversão alimentar (kg/dz e $\mathrm{kg} / \mathrm{kg}$ ) não diferiram significativamente entre os tratamentos. O peso do ovo, os percentuais de albúmen e da casca, a espessura da casca e a gravidade específica do ovo foram alterados pelos tratamentos, apresentando efeito quadrático. A massa de ovo e o percentual de gema não foram influenciados pelos tratamentos. O tratamento com $50 \%$ de substituição do milho, embora tenha proporcionado maior peso do ovo, resultou em menor percentual de casca. A coloração da gema foi alterada pelos tratamentos, reduzindo linearmente $(7,84 ; 7,52 ; 7,35 ; 5,32$ e 5,12$)$ à medida que se aumentou o nível de substituição do milho. Economicamente, o tratamento com $100 \%$ de substituição do milho pela farinha da apara de mandioca apresentou maior diferença no custo por quilo de ração, por dúzia de ovo e por caixa de ovo em relação aos demais. A substituição de até $100 \%$ do milho pela farinha da apara da mandioca não influencia a produção de ovos e a conversão alimentar. Entretanto, para substituição, deve-se considerar o custo desse resíduo em relação ao milho e dos pigmentantes a serem utilizados para corrigir a pigmentação da gema.

Palavras-chave: aves, desempenho, ingrediente, ovos

\section{Effect of corn replacement with cassava shaving flour in commercial laying hen diets}

\begin{abstract}
The economic and productive performances of the dietary corn replacement with cassava shavings flour were evaluated in 200 Lohmann LSL laying hens with 46 weeks old, kept in 25 cages. The experiment was analyzed as a complete randomized design with five treatments and five replicates of eight birds per experimental unit. The treatments consisted of five levels $(0,25,50,75$, and $100 \%)$ of corn replacement with cassava shavings flour. Quadractic effect on daily feed intake, with averages of $100.68,101.00,100.72,99.42$, and $99.50 \mathrm{~g}$, in the respective replacement levels, was observed. Viability, egg production and feeding conversion $(\mathrm{kg} / \mathrm{dz}$ and $\mathrm{g} / \mathrm{g}$ ) showed no significant differences. It was observed treatment effect (quadractic effect) on egg weight, albumen percentage, shell percentage, shell thickness and specific gravity. Egg mass and yolk percentage were not affected by the treatments. The $50 \%$ level treatment provided the lowest shell percentage in spite of presenting the highest egg weight. The egg yolk colour was affected by the treaments and showed linear decrease $(7.84,7.52,7.35,5.32$, and 5.12) as the corn replacement level increased. From an economical viewpoint, the $100 \%$ level treatment presented higher difference on the cost per kilogram of feed, egg-dozen, and egg-box in relation to the other treatments. It is possible to replace up to $100 \%$ of corn by with cassava shavings flours with no changes on egg yield and feeding conversion. However, the replacement will depend on the relative cost of corn and pigments to be used for correcting egg yolk pigmentation.
\end{abstract}

Key Words: eggs, ingredient, performance, poultry 


\section{Introdução}

A demanda cada vez maior de alimentos balanceados utilizados em rações para aves, o alto custo e a crescente utilização desses alimentos para consumo humano são fatores que têm incentivado os pesquisadores à busca por alimentos alternativos, principalmente os substitutos do milho (fonte de energia), como a farinha da mandioca. Em países tropicais, a mandioca (Manihot esculenta) é conhecida por vários nomes, como cassava, manioc, manihot, entre outros. Algumas variedades de mandioca in natura apresentam em sua composição o ácido hidrociânico, que, apesar de ser um composto tóxico, é termolábil, sendo inativado durante o processamento, não prejudicando a saúde dos animais (Viola et al., 1988). O uso de alimentos não convencionais exige a realização de testes visando à redução do custo das rações e ao bom desempenho dos animais (Franzoi et al., 1998). Squibb \& Wyld (1951) concluíram, a partir de vários experimentos, que a farinha de raspa de mandioca poderia substituir o milho integral ou parcialmente em rações para aves.

Substituindo $60 \%$ do milho pela farinha de mandioca em rações para poedeiras durante seis semanas, Hamid \& Jalaludin (1972) não encontraram efeito significativo no consumo de ração e na produção de ovos. Jalaludin \& Leong (1973), no entanto, verificaram redução na produção de ovos quando utilizaram $50 \%$ de farinha de raspas de mandioca em rações para poedeiras. Segundo diversos autores, a substituição integral do milho pela farinha de mandioca em rações para poedeiras não altera o percentual de postura e a qualidade interna dos ovos (Enriquez \& Ross, 1972; Montilla et al., 1973; Portal et al., 1977; Eshiett \& Ademosum, 1978). Enriques et al. (1977) fizeram a substituição de 50 e $100 \%$ do milho pela farinha de raspas de mandioca na alimentação de poedeiras durante 84 dias no período de produção, e não notaram diferenças na produção de ovos, no peso dos ovos e na conversão alimentar. Estudando dietas isocalóricas e isoprotéicas contendo 0 , 10,20 e $30 \%$ de resíduos de produção da farinha de mandioca em rações para aves de postura até 48 semanas de idade, Garcia et al. (1994) concluíram que é possível utilizar até 30\% desse resíduo na ração desde que se corrija a cor da gema com pigmentantes e que o custo da ração seja compatível. Uma das alternativas de substituição parcial do milho em rações para aves é o uso da casca de mandioca processada (Abau \& Onifade, 1996; Ikurior \& Onuh, 1996; Eruvbetine et al., 1996; Salami, 1999; 2000). Em poedeiras alimentadas com rações à base de milho, a média de coloração da gema seguindo a escala colorimétrica Roche, é de aproximadamente 7,0 pontos, observando-se que não é necessário adicionar pigmentantes artificiais quando as gemas possuem coloração de até 5,0 pontos (Barbosa de Brito \& Stringhini, 2003). O objetivo neste trabalho foi avaliar o efeito da utilização de níveis crescentes de farinha de apara de mandioca em substituição ao milho na ração sobre a qualidade do ovo e o desempenho de poedeiras comerciais.

\section{Material e Métodos}

O experimento foi realizado nas instalações do Setor de Avicultura da Faculdade de Ciências Agrárias da Universidade Federal do Amazonas - UFAM, situado no MiniCampus Universitário, em Manaus - AM. O período total do experimento foi de 140 dias (04 de outubro de 2003 a 21 de fevereiro de 2004), divididos em cinco intervalos de 28 dias. Foram utilizadas 200 poedeiras comercias da linhagem Lohmann LSL com 46 semanas de idade, criadas sob condições idênticas de alimentação e manejo. Todas as aves foram pesadas no início do experimento para uniformização das parcelas e apresentaram peso de 1,55 $\pm 0,065 \mathrm{~kg}$. A coleta de ovos foi realizada três vezes ao dia (às 8,11 e 17h) e, a seguir, foi registrada cada ocorrência.

$\mathrm{O}$ experimento foi conduzido em um delineamento experimental inteiramente ao acaso, com cinco tratamentos $(0,25,50,75$ e $100 \%$ de substituição do milho por farinha da apara da mandioca) e cinco repetições de oito aves. Durante todo o período experimental, as rações foram isoenergéticas $(2.750 \mathrm{kcal}$ de EM/ $\mathrm{kg})$, isoprotéicas $(17,0 \%$ de PB), isocálcicas (4,2\% de cálcio) e isofosfóricas $(0,40 \%$ de fósforo disponível). Como a farinha da apara de mandioca possui $3.109 \mathrm{kcal} / \mathrm{kg}$ de EM (inferior ao teor de EM milho, $3.400 \mathrm{kcal} / \mathrm{kg}$ ) e não possui pigmentos xantofílicos em sua composição, utilizou-se óleo de dendê nas rações como suplemento energético e como fonte de pigmentação da gema do ovo. A composição percentual e os níveis nutricionais das dietas que constituíram os tratamentos durante todo período experimental são apresentados na Tabela 1 .

$\mathrm{O}$ ingrediente utilizado para substituir o milho nas rações das aves foi a farinha da apara (ponta) da mandioca, obtida por meio de cortes nas pontas da raiz no momento da comercialização ao consumidor, forma tradicional de mostrar que o produto está em boas condições. Foram selecionadas as aparas de melhor aspecto, rejeitando-se o material suspeito de decomposição e as partes endurecidas da mandioca. A seguir, o material foi lavado para retirada de terra e posteriormente triturado em equipamento de trituração de grãos. Em seguida, foi mantido em estufa com ventilação forçada em temperatura de $36^{\circ} \mathrm{C}$ por um período de três dias. Após a retirada da estufa, o material foi 
Tabela 1 - Composição percentual e níveis nutricionais das dietas experimentais

Table 1 - Ingredient composition and nutritional levels of the experimental diets

\begin{tabular}{|c|c|c|c|c|c|}
\hline \multirow[t]{2}{*}{$\begin{array}{l}\text { Ingrediente (\%) } \\
\text { Ingredient }\end{array}$} & \multicolumn{5}{|c|}{$\begin{array}{c}\text { Nível de substituição do milho (\%) } \\
\text { Corn replacement level }(\%)\end{array}$} \\
\hline & 0 & 25 & 50 & 75 & 100 \\
\hline Farinha da apara de mandioca (Cassava shaving flour) & - & 11,79 & 24,64 & 36,94 & 50,33 \\
\hline Farelo de soja (Soybean meal) & 21,19 & 23,55 & 25,85 & 28,21 & 30,47 \\
\hline Farinha de carne e osso (Meat and bone meal) & 4,00 & 4,00 & 4,00 & 4,00 & 4,00 \\
\hline Fosfato bicálcico (Dicalcium phosphate) & 0,61 & 0,65 & 0,69 & 0,72 & 0,76 \\
\hline DL-metionina, 99\% (DL-methionine) & 0,10 & 0,12 & 0,13 & 0,14 & 0,15 \\
\hline Premix vitamínico (Vitamin premix) ${ }^{1}$ & 0,10 & 0,10 & 0,10 & 0,10 & 0,10 \\
\hline Premix mineral (Mineral premix) ${ }^{2}$ & 0,05 & 0,05 & 0,05 & 0,05 & 0,05 \\
\hline Antioxidante (Antioxidant) $)^{3}$ & 0,01 & 0,01 & 0,01 & 0,01 & 0,01 \\
\hline Sal (Salt) & 0,30 & 0,30 & 0,30 & 0,30 & 0,30 \\
\hline Energia metabolizável ( $\mathrm{kcal} / \mathrm{kg})$ (Metabolizable energy) & 2.750 & 2.750 & 2.750 & 2.750 & 2.750 \\
\hline Proteína bruta (\%)(Crude protein) & 17,00 & 17,00 & 17,00 & 17,00 & 17,00 \\
\hline Metionina (\%) (Methionine) & 0,35 & 0,35 & 0,35 & 0,35 & 0,35 \\
\hline Cálcio $(\%)$ (Calcium) & 4,20 & 4,20 & 4,20 & 4,20 & 4,20 \\
\hline Fósforo disponível (\%) (Available phosphorus) & 0,40 & 0,40 & 0,40 & 0,40 & 0,40 \\
\hline
\end{tabular}

triturado, ensacado e armazenado em local seco e ventilado para posterior utilização nas rações.

A determinação dos teores de extrativos nãonitrogenados e de energia metabolizável foi realizada por meio do cálculo descrito por Andriguetto et al. (1982). Pela diferença entre a composição total e somatório das frações obtidas no laboratório, determinou-se o teor de extrativo não-nitrogenado, cujo valor foi 78,05\%. A partir desta determinação, foi possível estimar o valor da EM da farinha de apara da mandioca (FAM), cujo resultado foi $3.109 \mathrm{kcal} / \mathrm{kg}$.

Avaliaram-se a viabilidade econômica (\%) das rações, o consumo de ração (g/ave/dia), a produção de ovos (\%), a conversão alimentar ( $\mathrm{kg} / \mathrm{dz}$ e kg/kg), o peso (g)e a massa de ovo (g/ave/dia), a gravidade específica do ovo $(\mathrm{g} / \mathrm{mL}$ de água), a porcentagem de gema, de albúmen e de casca, a espessura de casca ( $\mathrm{mm}$ ) e a coloração de gema. Nos dois últimos dias de cada ciclo (28 dias), logo após a coleta, os ovos foram pesados em balança eletrônica com aproximação de $0,01 \mathrm{~g}$. Antes de serem submetidos à avaliação, os ovos recém-postos foram armazenados durante uma hora até atingirem a temperatura ambiente. Para avaliação das características relacionadas à qualidade interna e da casca dos ovos, foram retirados ao acaso quatro ovos por unidade experimental. Os ovos foram mergulhados em seis soluções salinas com densidades de 1,075 a 1,100 para estimação da gravidade específica, conforme descrito por Hamiltom (1982). O peso da casca foi estimado nas cascas secas ao ar utilizando-se balança com aproximação de 0,01 g. A espessura de casca foi calculada segundo metodologia descrita por Potts \& Whashburn (1974) e Nordstrom \& Oustershout (1982); a espessura de cada pedaço ( 3 a $5 \mathrm{~mm}^{2}$ ) foi medida com micrômetro externo com curso de $25 \mathrm{~mm}$, leitura de $0,01 \mathrm{~mm}$ e exatidão de $0,002 \mathrm{~mm}$ e obtida a partir da média das quatro medidas. Para avaliação da cor da gema dos ovos, utilizou-se o leque colorimético Roche, com pontos de 1 a 15 .

As análises estatísticas foram realizadas utilizando-se o Sistema para Análises Estatísticas e Genética-SAEG (UFV, 1997), e as estimativas do nível de farinha da apara de mandioca em substituição ao milho, por meio do modelo de regressão. Na análise econômica, avaliaram-se o custo( $\mathrm{R} \$) / \mathrm{kg}$ de ração, o custo $(\mathrm{R} \$) /$ dúzia de ovo produzido e o custo $(\mathrm{R} \$) /$ caixa (360 ovos) de ovo produzido. 


\section{Resultados e Discussão}

$\mathrm{Na}$ análise da composição química da farinha da apara de mandioca (Tabela 2), observou-se que os valores de PB e FB desse alimento foram similares aos obtidos por Rostagno et al. (2000) com raspa integral de mandioca.

Como demonstrado na Tabela 3 , as médias de viabilidade nutricional das rações, de produção de ovos, de conversão alimentar (em kg de ração/dz de ovos e em g de ração/g de ovo) não foram significativamente influenciadas pelos tratamentos $(\mathrm{P}>0,05)$. Os níveis (75 e 100\%) de substituição do milho pela farinha da apara de mandioca não promoveram mortalidade, o que indica boa aceitação desse sucedâneo do milho em rações para aves de postura leves, como descrito por Viola et al. (1998), que afirmou que o ácido hidrociânico, um composto tóxico presente em algumas variedades de mandioca in natura, é inativado durante o processamento, não prejudicando a saúde dos animais. Os dados de viabilidade obtidos neste estudo estão dentro da faixa de normalidade prevista pelo Manual de Criação e Manejo Lohmann LSL (2003), que preconiza 95 e $90 \%$ de viabilidade com 46 e 66 semanas de idade, respectivamente.

A substituição do milho pela farinha da apara de mandioca em níveis crescentes não afetou a produção de ovos,

Tabela 2 - Composição química da farinha da apara de mandioca Table 2 - Chemical composition of cassava shaving flour

\begin{tabular}{lc}
\hline $\begin{array}{l}\text { Componente } \\
\text { Component }\end{array}$ & $\begin{array}{c}\text { Composição (\%) } \\
\text { Composition }\end{array}$ \\
\hline Umidade (humidity) & 12,23 \\
PB $(C P)$ & 2,43 \\
EE $(E E)$ & 0,35 \\
FB $(G F)$ & 4,91 \\
Cinzas $($ Ash $)$ & 2,03 \\
Ca & 0,08 \\
P total (Total P) & 0,10 \\
\hline
\end{tabular}

${ }^{1}$ Análise realizada no laboratório da VITAGRI Indústria e Serviços LTDA.

${ }^{1}$ Análise were perforned at the VITAGRI Indústria e Serviços LTDA Laboratory. embora o tratamento controle tenha sido 6,21\% superior (em valores relativos) àquele com $100 \%$ de substituição do milho pela farinha de apara de mandioca. Esse resultado corrobora os obtidos por Hamid \& Jalaludin (1972), que, durante seis semanas, substituíram $60 \%$ do milho pela farinha de mandioca em rações para poedeiras e não encontraram efeito significativo na produção de ovos e na conversão alimentar. Do mesmo modo, Enriques et al. (1977) não encontraram diferenças na produção de ovos e na conversão alimentar quando substituíram 50e 100\% do milho pela farinha de raspas de mandioca na alimentação de poedeiras. Jalaludin \& Leong (1973), no entanto, registraram efeito significativo sobre a produção de ovos quando utilizaram $50 \%$ de farinha de raspas de mandioca em rações para poedeiras.

Apesar dos valores numéricos muito próximos, o consumo de ração foi influenciado pelos tratamentos $(\mathrm{P}<0,05)$, apresentando efeito quadrático, representado pela equação $\hat{Y}=100,838+0,00138286 \mathrm{X}-0,000171429 \mathrm{X}^{2}, \mathrm{r}^{2}=0,77$ (Tabela 3). Este resultado contraria os dados reportados por Hamid \& Jalaludin (1972), que substituíram 60\% do milho pela farinha de mandioca em rações para poedeiras e não observaram efeito significativo para essa variável.

O bom desempenho das aves alimentadas com ração contendo $100 \%$ de farinha de apara da mandioca pode ser explicado pela similaridade da composição nutricional desse alimento em relação ao milho e pela adição de óleo de dendê como suplemento energético às rações, o que proporcionou menor pulverulência e contribuiu para o melhor aproveitamento pelas aves.

Os tratamentos não influenciaram $(\mathrm{P}>0,05)$ a massa de ovo e o percentual de gema do ovo (Tabela 4). Os resultados corroboram relatos (Enriquez \& Ross, 1972; Montilla et al., 1973; Portal et al., 1977; Eshiett \& Ademosum, 1978) de que a substituição integral do milho pela farinha de mandioca em rações para poedeiras não afeta a qualidade interna dos ovos.

$\mathrm{O}$ peso do ovo sofreu efeito linear $(\mathrm{P}<0,05)$, representado pela equação de regressão $\hat{Y}=58,8640+0,0210 X$,

Tabela 3 - Resultados médios de desempenho de poedeiras alimentadas com rações formuladas com diferentes níveis de substituição do milho pela farinha da apara de mandioca

Table 3 - Average performance values of laying hens fed diets with increasing corn replacement levels with cassava shaving flour

\begin{tabular}{|c|c|c|c|c|c|c|c|}
\hline \multirow[t]{2}{*}{$\begin{array}{l}\text { Variável } \\
\text { Variable }\end{array}$} & \multicolumn{5}{|c|}{$\begin{array}{l}\text { Nível de substituição do milho (\%) } \\
\text { Corn replacement level }(\%)\end{array}$} & \multirow[t]{2}{*}{$r^{2}$} & \multirow[t]{2}{*}{$\mathrm{CV}(\%)$} \\
\hline & 0 & 25 & 50 & 75 & 100 & & \\
\hline Viabilidade $(\%)$ (Viability) & 95,00 & 95,00 & 92,50 & 100,00 & 100,00 & - & 7,98 \\
\hline Consumo de ração ${ }^{1}$ (g/ave/dia) (Feed intake, g/bird/day) & 100,68 & 101,00 & 100,72 & 99,42 & 99,50 & 0,77 & 3,65 \\
\hline Produção de ovos (\%) (Egg production, \%) & 82,83 & 81,72 & 82,32 & 81,61 & 77,68 & - & 4,48 \\
\hline Conversão alimentar $(\mathrm{kg} / \mathrm{dz})$ (Feed:egg production ratio) & 1,51 & 1,50 & 1,53 & 1,46 & 1,54 & - & 3,86 \\
\hline Conversão alimentar $(\mathrm{kg} / \mathrm{kg})$ (Feed: gain ratio) & 1,92 & 1,97 & 1,89 & 1,92 & 1,97 & - & 5,18 \\
\hline
\end{tabular}

\footnotetext{
${ }^{1}$ Efeito quadrático $(P<0,05)$.
} 
$\mathrm{r}^{2}=0,38$, observando-se o melhor resultado $(65,41 \mathrm{~g})$ nas aves alimentadas com $50 \%$ de substituição do milho pela farinha da apara de mandioca. Esse resultado diverge dos reportados por Enriques et al. (1977), que não encontraram diferença no peso do ovo quando substituíram 50 e $100 \%$ do milho pela farinha de raspas de mandioca na alimentação de poedeiras.

Os tratamentos influenciaram $(\mathrm{P}<0,05)$ a porcentagem de albúmen, verificando-se efeito quadrático pela equação de regressão $\hat{Y}=58,291+0,0478766 \mathrm{X}-0,000267886 \mathrm{X}^{2}$, $\mathrm{r}^{2}=0,43$. A substituição de $100 \%$ do milho pela farinha da apara da mandioca proporcionou maior percentual de albúmen, indicando uma relação estreita com o peso do ovo. Os ovos mais pesados foram obtidos nos níveis 50 e $100 \%$ de substituição do milho pela farinha de apara da mandioca, contrariando relatos de Enriquez \& Ross (1972), Montilla et al. (1973), Portal et al. (1977) e Eshiett \& Ademosum, (1978), que substituíram integralmente o milho pela farinha de mandioca em rações para poedeiras e não observaram alteração no percentual de albúmen.

A porcentagem de casca foi influenciada pelos tratamentos $(\mathrm{P}<0,05)$ e apresentou efeito quadrático com a equação de regressão $\hat{Y}=13,0174-0,0390343 X+$ $0,000353143 \mathrm{X}^{2}, \mathrm{r}^{2}=0,82$. A espessura de casca também apresentou efeito quadrático $(\mathrm{P}<0,05)$ com equação de regressão $\hat{\mathrm{Y}}=0,189766-0,00108926 \mathrm{X}+0,0000774857 \mathrm{X}^{2}$, $\mathrm{r}^{2}=0,66 \mathrm{e}$ foi maior para ovos produzidos por aves alimentadas com rações contendo $100 \%$ de milho, provavelmente, em virtude da baixa concentração de cálcio na farinha em comparação ao milho, presente nas demais rações. Apesar dos valores semelhantes, a gravidade específica foi influenciada pelos tratamentos $(\mathrm{P}<0,05)$, apresentando efeito quadrático com a equação de regressão $\hat{\mathrm{Y}}=1,08110$ $0,0000778286 \mathrm{X}+0,00000107429 \mathrm{X}^{2}, \mathrm{r}^{2}=0,76$.
Os tratamentos influenciaram significativamente $(\mathrm{P}<0,05)$ a coloração da gema, que apresentou efeito linear negativo com a equação de regressão $\hat{Y}=8,15680$ $0,0305440 X, r^{2}=0,84$. Segundo Barbosa de Brito \& Stringhini (2003), nos casos de substituição integral do milho pela farinha de apara de mandioca, apesar do menor nível de pigmentação da gema, não é necessário adicionar pigmentantes artificiais quando as gemas apresentam até 5,0 pontos de escores colorimétricos na escala Roche.

O custo das rações foi calculado considerando os preços por quilo das matérias-primas utilizadas no experimento no mês de outubro de 2003: milho, $\mathrm{R} \$ 0,42$; farinha de apara de mandioca, $R \$ 0,25$; farelo de soja, $R \$ 0,77$; farinha de carne e osso, $\mathrm{R} \$ 0,51$; óleo de dendê, $\mathrm{R} \$ 0,50$; calcário, R $\$ 0,26$; fosfato bicálcico, R \$ 1,20; DL- Metionina, $\mathrm{R} \$ 9,00$; premix vitamínico, $\mathrm{R} \$ 7,50$; premix mineral, $\mathrm{R} \$ 4,70$; BHT, R \$ 50,00; sal, R \$ 0,30.

Pela análise dos custos das rações (Tabela 5), verifica-se que, no tratamento com $100 \%$ de milho, o custo da ração foi de $\mathrm{R} \$ 0,52 / \mathrm{kg}$ mas, à medida que se aumentou ao nível de farinha da apara de mandioca nas rações, o custo por quilo diminuiu, chegando a diferença de $\mathrm{R} \$ 0,06$ por quilo entre o tratamento com $100 \%$ de milho e aquele com $100 \%$ de farinha da apara de mandioca. Este valor parece pequeno, porém se colocado em escala, resulta em uma diferença expressiva.

Os custos por dúzia de ovos e por caixa de ovos (Tabela 5) apresentaram tendência semelhante, com redução gradativa do tratamento com $100 \%$ de milho para o tratamento com $100 \%$ de farinha da apara de mandioca. A diferença entre estes tratamentos quanto ao custo por dúzia de ovo foi de $\mathrm{R} \$ 0,08$ e, quanto ao custo por caixa de ovo, foi mais acentuada, de $R \$ 2,40$, que não deixa de ser expressiva quando colocada em escala.

Tabela 4 - Qualidade do ovo de poedeiras alimentadas com rações formuladas com diferentes níveis de substituição do milho pela farinha da apara de mandioca

Table 4- Quality of the egg of laying hens fed diets with increasing corn replacement levels with cassava shaving flour

\begin{tabular}{|c|c|c|c|c|c|c|c|}
\hline \multirow{3}{*}{$\begin{array}{l}\text { Variável } \\
\text { Variable }\end{array}$} & \multirow{2}{*}{\multicolumn{5}{|c|}{$\begin{array}{c}\text { Nível de substituição do milho (\%) } \\
\text { Corn replacement level }(\%)\end{array}$}} & \multirow[t]{3}{*}{$\mathrm{r}^{2}$} & \multirow[t]{3}{*}{$\mathrm{CV}(\%)$} \\
\hline & & & & & & & \\
\hline & \multicolumn{5}{|c|}{50} & & \\
\hline Peso do ovo (g) ${ }^{1}$ (Egg weight) & 63,35 & 62,72 & 65,41 & 63,38 & 65,15 & 0,31 & 2,39 \\
\hline Massa de ovo (g/ave/dia) (Egg mass, g/bird/day) & 54,96 & 54,45 & 55,93 & 58,44 & 54,02 & - & 3,60 \\
\hline Gema $(\%)($ Egg yolk $)$ & 27,36 & 27,97 & 29,79 & 27,85 & 26,62 & - & 4,87 \\
\hline Albúmen $(\%)^{2}$ (Albumen) & 58,51 & 59,51 & 60,51 & 60,31 & 60,74 & 0,94 & 1,64 \\
\hline Casca $(\%)^{2}($ Shell $)$ & 9,93 & 9,53 & 8,67 & 9,18 & 9,64 & 0,82 & 5,01 \\
\hline Espessura de casca ${ }^{2}(\mathrm{~mm})$ (Shell thickness) & 0,389 & 0,368 & 0,359 & 0,345 & 0,361 & 0,93 & 6,13 \\
\hline Gravidade específica ${ }^{2}$ (g/mL de água) & 1,081 & 1,080 & 1,079 & 1,082 & 1,084 & 0,91 & 0,081 \\
\hline \multicolumn{8}{|l|}{ Specific gravity $(\mathrm{g} / \mathrm{mL}$ of water $)$} \\
\hline Coloração da gema ${ }^{1}$ (Egg yolk color) & 7,84 & 7,52 & 7,35 & 5,32 & 5,12 & 0,86 & 2,61 \\
\hline
\end{tabular}

1 Efeito linear (Linear effect) $(\mathrm{P}<0,05)$.

2 Efeito quadrático (Quadratic effect) $(\mathrm{P}<0,05)$. 
Tabela 5 - Custo $(R \$)$ por quilo de ração, custo $(R \$)$ por dúzia de ovo e custo $(R \$)$ por caixa de ovo

Table 5 - Cost $(R \$)$ per $\mathrm{kg}$ of diet, cost $(R \$)$ per dozen of egg and cost (R\$) per box of egg

\begin{tabular}{lccc}
\hline $\begin{array}{l}\text { Nível de } \\
\text { substituição (\%) } \\
\text { Replacement level (\%) }\end{array}$ & $\begin{array}{c}\text { Custo }(\mathrm{R} \$) / \mathrm{kg} \\
\text { Cost }(R \$) / \mathrm{kg}\end{array}$ & $\begin{array}{c}\text { Custo }(\mathrm{R} \$) / \mathrm{dz} \\
\text { Cost }(R \$) / \mathrm{dz}\end{array}$ & $\begin{array}{c}\text { Custo }(\mathrm{R} \$) / \mathrm{cx} \\
\text { Cost }(R \$) / \mathrm{cx}\end{array}$ \\
\hline 0 & 0,52 & 0,78 & 23,4 \\
25 & 0,51 & 0,76 & 22,8 \\
50 & 0,49 & 0,75 & 22,5 \\
75 & 0,48 & 0,70 & 21,0 \\
100 & 0,46 & 0,70 & 21,0 \\
\hline
\end{tabular}

Ressalta-se que os resultados de desempenho e qualidade do ovo obtidos neste estudo estão na faixa de valores considerados normais e aceitáveis, o que reflete a importância de estudar fontes alternativas e alimentos não convencionais visando reduzir o custo das rações, mas mantendo o bom desempenho dos animais (Franzoi et al., 1998). Essa afirmação corrobora os resultados obtidos por Garcia et al. (1994), que concluíram ser possível utilizar até 30\% de resíduos da produção de farinha de mandioca em rações para aves de postura de até 48 semanas de idade desde que o custo da ração seja compatível.

\section{Conclusões}

É possível substituir $100 \%$ do milho pela farinha da apara de mandioca sem alterar a produção de ovos e conversão alimentar. Entretanto, a substituição dependerá do custo desse alimento em relação ao milho e do custo dos pigmentantes utilizados para corrigir a coloração da gema.

\section{Agradecimento}

À VITAGRI Indústria e Serviços LTDA, pela análise bromatológica da farinha da apara da mandioca.

À EMBRAPA - Amazônia Ocidental, pela doação do óleo de dendê.

\section{Literatura Citada}

ABAU, O.A.; ONIFADE, A.A. Effects of cassava waste sustitution for maize in weaner rabbit diets. Bulletin Animal Hith, v.44, p.167-172, 1996

ANDRIGUETTO, J.M.; PERLY, L.; MINARDI, I. et al. Nutrição animal. 1.ed. São Paulo: Nobel, 1982. 395p.

BARBOSA DE BRITO, A.; STRINGHINI, J.H. Avaliação do gérmen integral de milho na nutrição de poedeiras comerciais. Avicultura Industrial, n.10, p.22-24, 2003.

ENRIQUES, V.; ARTEGA, F.C.; AVILA, G.F. Harina de yuca (Manihot esculenta) em dietas para pollos de engorda y gallinas em postura. Técnicas Pecuárias Méxicanas, v.32, p.53-57, 1977
ENRÍQUEZ, F.W.; ROSS, E. Cassava root meal in grower and layer diets. Poultry Science, v.51, p.228-232, 1972.

ERUVBETINE, D.; OGUNTONA, E.B.; JAMES, I.J. et al.Cassava (Manihot esculenta) as an energy source in diets for cockerels. Journal of Animal Science, v.11, p.99-101, 1996.

ESHIETT, N.; ADEMOSUM, A.A. The use of cassava root meal in chicken rations in Nigéria. In: CONGRESSO MUNDIAL DE AVICULTURA, 1978, Rio de Janeiro. Anais... Rio de Janeiro: World's Poultry Science Association, 1978. p.1701-1709.

FRANZOI, E.E.; SIEWERDT, F.; RUTZ, F. et al. Desempenho de frangos de corte alimentados com diferentes níveis de farelo de canola. Ciência Rural, v.28, n.4, p.683-689, 1998.

GARCIA, E.A.; MENDES, A.A.; GONZALES, E. et al. Utilização de resíduo da produção de farinha de mandioca na alimentação de poedeiras. Veterinária e Zootecnia, n.6, p.123-129, 1994.

HAMID, K.; JALALUDIN, S. Utilization of tapioca in rations for laying poultry. Malays Agriculture Research, v.1, p.48-53, 1972.

HAMILTON, R.M.G. Methods and factors that affect the measurement of egg shell quality. Poultry Science, v.61, n.6, p.2022-2039, 1982.

IKURIOR, S.A.; ONUH, S.O. Assessment of pratical potential of cassava peels meal for growing and growing-finishing pigs in sub-humid tropics. Bulletin Animal Hith, v.44, p.209214, 1996.

JALALUDIN, S.Y.; LEONG, S.K. Response of laying hens to low and high levels of tapioca meal. Malays Agriculteure Research, v.2, n.1, p.47-51, 1973.

MANUAL DE CRIAÇÃO E MANEJO LOHMAN LSL. Controle de produção avícola. Uberlândia: Granja Planalto, 2003. 26p.

MONTILLA, J.J.; WIEDENHOFER, H.; REVERON, A.E. et al. Sustitución de la harina de maíz por harina de raíz de yuca para ponedoras. In: CONGRESO LATINO AMERICANO DE AVICULTURA, 1973, São Paulo. Trabalhos Técnicos... São Paulo: 1973. n.3, p.95.

NORDSTROM, J.O.; OUSTERSHOUT, L.E. Estimation of shell weight and shell thickness from egg specific gravity and egg weight. Poultry Science, v.61, p.1991-1995, 1982.

PORTAL, C.M.; TINEO, J.; ROMERO, B. Utilización de harina de yuca en dietas para ponedoras. Revista Facultad de Agronomía, v.3, p.27-35, 1977.

POTTS, P.I.; WASHBURN, K.W. Shell evaluation of white and brown egg strains by deformation, breaking strength, shell thickness and specific gravity. Poultry Science, v.53, p.1123$1128,1974$.

ROSTAGNO, H.S.; ALBINO, L.F.T.; DONZELE, J.L. et al.Tabelas brasileiras para aves e suínos: composição de alimentos e exigências nutricionais. Viçosa, MG: Universidade Federal de Viçosa, 2000. 141p.

SALAMI, R.I. The use of two empirical methods of substitution of feedstuffs: parboiled cassava peel meal versus maize in the diets of growing cockerels. Nigeria Journal Animal Production, v.26, p.78-83, 1999.

SALAMI, R.I. Preliminary studies on the use of parboiled cassava peel meal as a substitute for maize in layers' diets. Tropical Agriculture, v.77, p.199-204, 2000.

SQUIBB, R.L.; WYLD, M.K. Effects of yuca meal in baby chicks rations. Turrialba, v.1, p.298-299, 1951

UNIVERSIDADE FEDERAL DE VIÇOSA - UFV.SAEG - Sistema de análise estatística e genética. Versão 7.0, Viçosa, MG, 1997.

VIOLA, S.; ARIELI, Y.; ZOHAR, G. Unusual feedstuffs (tapioca and lupin) as ingredients for carp and tilapia feeds in intensive culture. Israel Journal Aquaculture, v.40, n.1, p.29-34, 1988. 